\title{
Learn as if you were to live forever
}

\author{
Yoshiki Hirooka ${ }^{1}$
}

Received: 21 December 2020 / Accepted: 25 December 2020

(c) The Japan Society of Ultrasonics in Medicine 2021

I was in Shanghai in early January 2020 for a gastrointestinal endoscopy-related workshop. I remember hearing at the time that some unknown form of pneumonia began going around in Wuhan around the end of November 2019. I imagine that I would have had a very difficult time returning to Japan if the workshop had been held a week later. I am writing this Editor's Note on December 18, 2020. It has been less than a year since I was in Shanghai, and the world has changed drastically. We are currently experiencing the third wave of COVID-19. I feel like some countries are being hit harder than others. Perhaps, so far, Japan is faring better than some countries. I pray that the COVID-19 situation has improved around the world, if even by a little, by the time this issue is published and reaches you.

I have always enjoyed learning new things. I also like to relearn things I have learned before. I am a gastroenterologist, and learning new things related to gastroenterology and relearning things I have begun to forget are, in a sense, an obligation. I like to learn things unrelated to the field of gastroenterology that I am not obligated to learn. I have a strong interest in learning things not related to medicine. I sometimes have the urge to study classical Japanese literature. I sometimes feel like reading classical literature aloud. Studying classical literature is not new to me. I studied it before in preparation for my university entrance exams, and I have completely forgotten what I learned. I can remember my high school classical Japanese literature teacher encouraging us to learn the basics of the classics now because we would surely have the urge to read classical literature once we reached a certain age. Perhaps I have reached that age. Reading classical literature helps me relax after I have finished my work for the day. What that teacher said was true. And this does not apply only to classical literature. Relearning math, physics, and so on and learning subjects I have

Yoshiki Hirooka

hirooka@med.nagoya-u.ac.jp

1 Department of Gastroenterology and Gastroenterological Oncology, Fujita Health University School of Medicine, Aichi, Japan not learned before are surprisingly relaxing. Such "learning" sometimes leads to new insights related to medicine. Recently, however, I more frequently find myself questioning whether there is any point to it. I wonder if it is due to a pessimistic mood over COVID-19, or due to my age, or for some other reason? I am not sure. At any rate, I more frequently think about whether there is any point to continuing to learn given that I will perish one day.

"Learn as if you were to live forever" is a quote from Mahatma Gandhi. I think I stopped trying to find meaning in learning as much after encountering this quote. My thinking now is that "we learn because we want to learn" is the right approach. My fear of perishing subsides while I am learning. Actually, "Live as if you were to die tomorrow" is the first half of the above quote. I personally cannot live such a life that only special people can realize, so I have conveniently used only the latter half of Gandhi's words.

The first issue of JMU in 2021 includes a wide variety of articles ranging from basic to clinical research. In terms of clinical research, almost every field related to ultrasound is covered. In our next issue, we plan to include multiple features, which have been well received by our readers. In addition, as the article titled "Point-of-care lung ultrasound for assessment of pneumonia: a narrative review in the COVID19 era" by Kameda et al. contains very timely information, we have decided to make it openly available to all for free. We hope that it will be read by many people working in COVID-19-related areas.

The JMU Editorial Board will do its utmost again this year to publish articles that will be helpful to all of our readers. Thank you for your continued support.

Publisher's Note Springer Nature remains neutral with regard to jurisdictional claims in published maps and institutional affiliations. 